\title{
Cistoplastia experimental em coelhos (Oryctolagus cuniculus) com peritônio bovino conservado em glicerol a $98 \%$
}

\author{
Experimental cystoplasty in rabbits (Oryctolagus cuniculus) with bovine peritoneum conserved \\ in $98 \%$ glycerol
}

\author{
Tatiana Catelan de Oliveira' ${ }^{\mathrm{I}}$ Alessandra Regina Freixo Scavone ${ }^{\mathrm{I}}$ \\ Márcia Rita Fernandes Machado ${ }^{I^{*}}$ Bárbara Cristina Mazzucatto $^{\mathrm{II}}$
}

\section{RESUMO}

Neste estudo foi implantado um retalho de membrana peritoneal bovina em substituição a um fragmento da face ventral da bexiga de coelhos albinos, raça Nova Zelândia, adultos, machos não-castrados $(n=12)$, com o intuito de avaliar o processo de reparação tecidual no que se refere à biocompatibilidade, à capacidade de reparação tecidual e a possíveis complicações. Aos sete, 14, 30 e 60 dias de pósoperatório, os animais foram eutanasiados, três em cada período, mediante o emprego de tiopental sódico (200mg $\left.\mathrm{kg}^{-1}\right)$, para posterior avaliação macroscópica e análise histopatológica da interface do implante com o tecido nativo. Macroscopicamente, foram observadas, em todos os períodos, aderências de estruturas adjacentes ao local do implante, presença de cálculos e ausência de sinais de rejeição. Sob microscopia de luz, aos sete, 14 e 30 dias de observação, o implante ainda estava presente, havia intensa reação inflamatória mista, neovascularização, fibroplasia e escassas fibras musculares, contudo, o epitélio e a lâmina própria não estavam reconstituídos. Aos 60 dias de avaliação, o implante não estava mais presente e todas as camadas vesicais encontravam-se reparadas. O implante foi biocompatível $e$ forneceu arcabouço para orientação e desenvolvimento das camadas teciduais da bexiga, mediante processos de reparação, restabelecendo a estrutura do órgão.

Palavras-chave: implante, membrana biológica, bexiga, coelhos.

\section{ABSTRACT}

Bovine peritoneum was utilized to replace a section of ventral face of the bladder of New Zealand rabbits, adult and entire males $(n=12)$ with the purpose of evaluating the tissue repair process in regard of its biocompatility, scar formation ability and possible complications. The animals were euthanized at 7, 14, 30 and 60 days post operative, three in each period, by the use of sodium thiopental (200 $\mathrm{mg} \mathrm{kg}^{-1}$ ), followed by macroscopic evaluation and histopathological analysis of the implant interface with the native tissue. Macroscopically it was observed, in all time periods, structure adherence to the implant site, presence of calculi and absence of rejection signs. Under light microscopy at the $7^{\text {th }}, 14^{\text {th }}$ and $30^{\text {th }}$ observation days, the implant was present; a mixed intense inflammatory reaction could be observed, neovascularization, fiberplasic process and rare muscle fibers, however the epithelium and sheath weren't also reconstituted. At the $60^{\text {th }}$ day of evaluation the implant wasn't anymore present and all vesicle layers were repaired. The implant was biocompatible and provided the mainframe for orientation and development of the tissue layers of the bladder, through repairing processes thus reestablishing the organ's structure.

Key words: implant, biological membrane, bladder, rabbits.

\section{INTRODUÇÃO}

A utilização de membranas biológicas, no Brasil, teve início a partir da implantação experimental de dura-máter homóloga, conservada em glicerina, na substituição de segmento dural de cães (PIGOSSI, 1967).

O peritônio bovino é uma membrana biológica de origem animal, composta quase que exclusivamente de colágeno, possuindo, portanto, baixa antigenicidade. Além disso, já há algum tempo sabe-se que este material apresenta fácil obtenção e estocagem, esterilização viável, praticidade ao

'Departamento de Morfologia e Fisiologia Veterinária, Faculdade de Ciências Agrárias e Veterinárias (FCAV), Universidade Estadual Paulista (UNESP), Campus Jaboticabal. Via de Acesso Prof. Paulo Donato Castelanne, s/n, 14884-900, Jaboticabal, SP, Brasil. Email: mrfmachd@fcav.unesp.br. *Autor para correspondência.

"Faculdade São Luís, Jaboticabal, SP, Brasil. 
manuseio e custo acessível (ALVARENGA, 1992). Ademais, desde a década de 80 alguns autores (DALECK et al., 1987; DALECK et al., 1988; ALVARENGA, 1992) relatam que ao se conservar este tipo de membrana biológica em glicerina a $98 \%$, sob temperatura ambiente, por período superior a 30 dias, preserva-se sua textura e seu grau de elasticidade e sua resistência.

Considerando-se que uma prótese a ser implantada na bexiga deve incorporar características básicas como biocompatibilidade, e capacidade de distensão, não propiciar a formação de cálculos, ser impermeável, não-carcinogênica, e estéril e manter as propriedades urodinâmicas (PENTERMANN et al., 1985), objetivou-se avaliar o processo de reparação tecidual da membrana peritônio bovino, quando implantada em substituição a fragmento da parede ventral da bexiga, em coelhos. Foram avaliadas a biocompatibilidade, a capacidade de reparação e as possíveis complicações.

\section{MATERIAL E MÉTODOS}

Foram utilizados 12 coelhos albinos, raça Nova Zelândia, adultos, machos não-castrados e com peso entre 2 a 2,5kg, que foram mantidos em gaiolas individuais, de dimensões de 80 x 50 × 35cm, localizadas no Biotério do Departamento de Morfologia e Fisiologia Animal da FCAVJ-UNESP e receberam ração comercial, própria para a espécie, e água à vontade.

A colheita da membrana peritônio bovino foi realizada no frigorífico Bom Demais, localizado na cidade de Taquaritinga, Estado de São Paulo, Brasil, devidamente inscrito nos Órgãos de Vigilância Sanitária, ou seja, proveniente de animais hígidos. Após a coleta, os fragmentos de peritônio foram lavados em água corrente para retirada de sujidades, sangue e tecidos aderentes, sendo, em seguida, acondicionados em frasco de vidro contendo glicerol a $98 \%$, sob temperatura ambiente, por período superior a 30 dias (DALECK et al., 1988).

Para realização da técnica de cistoplastia, posteriormente ao jejum alimentar e hídrico de 12 e 4 horas, respectivamente, cada coelho foi submetido à medicação pré-anestésica com acepromazina 1\% (1mg $\mathrm{kg}^{-1}$ ) e butorfanol $\left(1 \mathrm{mg} \mathrm{kg}^{-1}\right)$, ambos por meio da via intramuscular (IM). Em seguida, a indução anestésica foi conduzida com a associação comercial de tiletamina e zolazepam (Zoletil ${ }^{\circledR}$, Virbac), na dose de $10 \mathrm{mg} \mathrm{kg}^{-1}$, via intravenosa (IV), e mantida mediante emprego do anestésico volátil halotano, por meio de máscara conectada a um circuito semifechado. Com o animal posicionado em decúbito dorsal, foi realizada a tricotomia da região abdominal caudal, seguida de antisepsia com iodopovidona degermante, álcool e iodopovidona.

Durante o período transcirúrgico, foi realizado incisão de pele retro-umbilical na linha média do abdômen, divulsão do tecido subcutâneo, abertura, em estocada, da musculatura abdominal sobre a linha alba, com seu posterior prolongamento cranial e caudal. A bexiga foi isolada do restante da cavidade com compressas úmidas e, quando repleta, foi feita uma cistocentese intra-operatória como preconizado por STONE (1996) e por FOSSUM (2002).

Foram colocados dois pontos de reparo na extremidade cranial e dois na extremidade caudal do plano a ser incisado, para auxiliar e facilitar a manipulação do órgão (STONE, 1996) e, de acordo com NUININGA et al. (2004), da face ventral da vesícula urinária, após incisão em estocada, retirou-se um fragmento de $1,5 \times 1,5 \mathrm{~cm}$, o qual se substituiu por retalho de peritônio bovino, de mesma dimensão (Figura 1A). Previamente ao seu implante, o retalho foi colocado em recipiente estéril, imerso em aproximadamente $20 \mathrm{~mL}$ da solução fisiológica de $\mathrm{NaCl}$ 0,9\% acrescida de solução contendo ampicilina sódica (100 $\mathrm{mg} \mathrm{mL}^{-1}$ ), por 10 minutos (DALECK et al., 1987; DALECK et al., 1988). Para fixação do implante ao órgão, utilizou-se sutura com fio absorvível sintético multifilamentar (Poliglactina 910) 5-0 em único plano.

Fundamentado em NUININGA et al. (2004) e KROPP (1998), ao redor da interface do implante com o tecido nativo, foram fixados, transpassando as camadas sero-muscular, quatro pontos simples e separados, com fio inabsorvível sintético monofilamentar (náilon) 3-0, para a identificação futura da região do implante.

No período pós-operatório, nenhum coelho foi mantido com sonda uretral. Foram instituídas terapias antimicrobiana com sulfa-trimetoprim $\left(15 \mathrm{mg} \mathrm{kg}^{-1}\right)$, via oral (VO), a cada 12 horas, durante sete dias consecutivos e antiinflamatória com flunexina-meglumina $\left(1 \mathrm{mg} \mathrm{kg}^{-1}\right)$, via subcutânea (SC), a cada 24 horas durante três dias. A limpeza da ferida cirúrgica foi feita com iodopovidona, a cada 24 horas, por sete dias. Para evitar deiscência de sutura de pele decorrente de traumas, foram colocados em todos os animais colar elizabetano e uma bandagem de esparadrapo na região das falanges proximal, média e distal dos membros pélvicos.

Durante os sete dias subseqüentes ao procedimento cirúrgico, avaliou-se clinicamente cada animal quanto ao aspecto da ferida cirúrgica, ao estado geral e do aspecto da urina e das fezes e foi aferida a temperatura retal. 


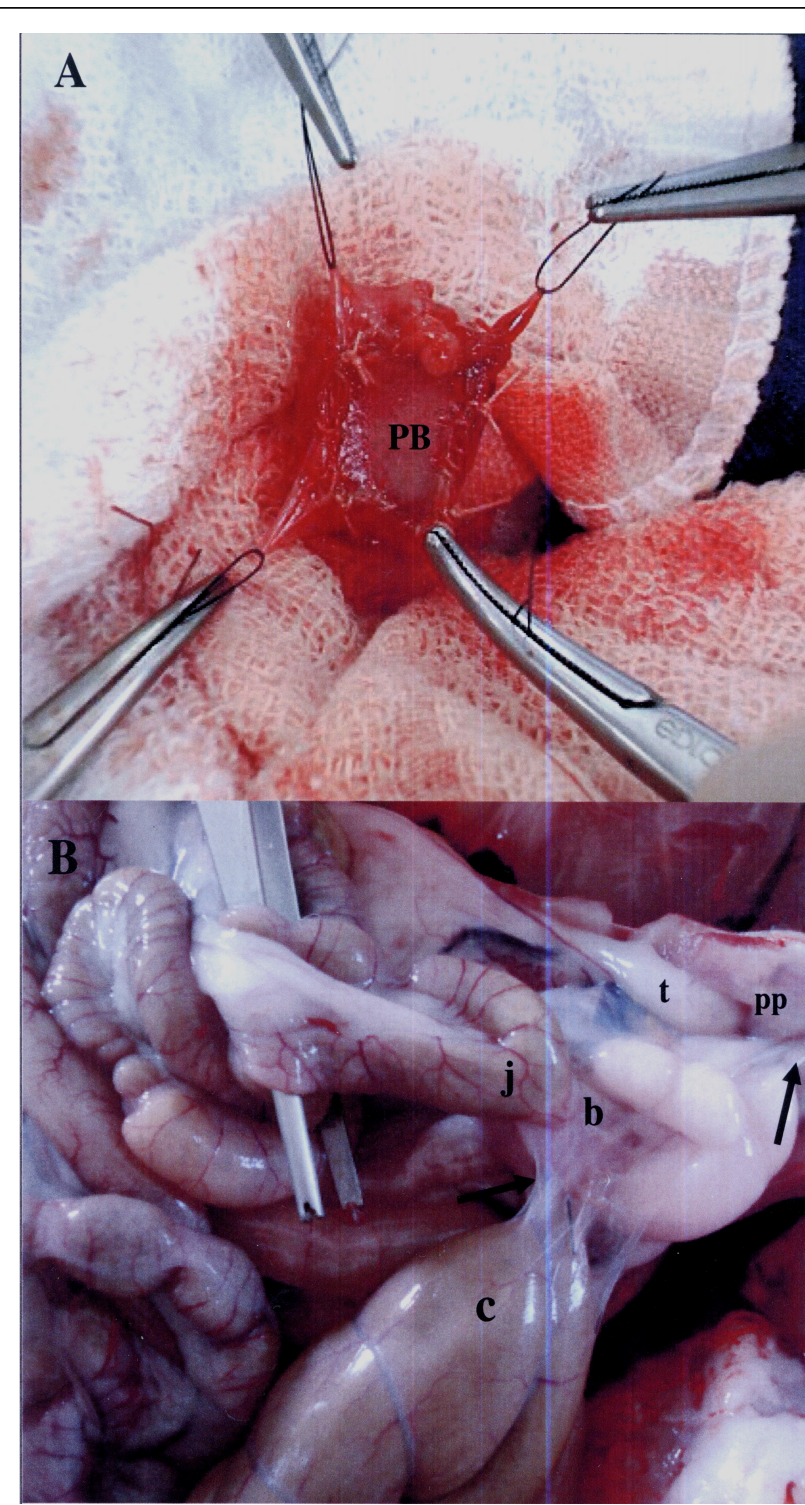

Figura 1 - A. fotografia da bexiga de coelho, macho, adulto, de raça Nova Zelândia, no período transoperatório, na qual se verifica o implante de peritônio bovino (PB) totalmente fixado à parede vesical. B. Fotografia vista da região ventral interna do abdômen de coelho, macho, adulto, da raça Nova Zelândia, eutanasiado aos 60 dias de pósoperatório, em que se observam aderências $(\rightarrow)$ da bexiga (b), na região do implante de peritônio bovino, ao ceco (c), ao jejuno (j), ao testículo (t) e ao peritônio parietal (pp) da parede ventral do abdômen.

Para serem efetuadas avaliações macroscópica e histopatológica, nos tempos de sete, 14, 30 e 60 dias pós-operatórios, em cada um desses períodos, três coelhos foram submetidos à eutanásia utilizando-se tiopental sódico (200 $\mathrm{mg} \mathrm{kg}^{-1}$ ) por via IV.

Na avaliação macroscópica, investigou-se a região do implante quanto às seguintes ocorrências: aderências, falhas no implante, necrose, fístula, inflamação local, além de se verificar a presença de muco, de encrustrações e de cálculos na luz do órgão. Quando presentes, os cálculos foram enviados ao laboratório de Patologia Clínica Veterinária da FCAVJ-UNESP para análise. Se a bexiga estivesse repleta, colhia-se quantidade significativa de urina para posterior análise laboratorial (urinálise e sedimentoscopia) e também urocultura, realizadas mediantes técnicas usuais preconizadas pelos laboratórios de Patologia Clínica Veterinária e de Microbiologia Veterinária, ambos da FCAVJUNESP.

Após avaliação macroscópica, fragmentos de aproximadamente $1 \mathrm{~cm}^{2}$, que continham a interface implante e tecido nativo, foram excisados, fixados em solução tamponada de formol a $10 \%$ e encaminhados ao Departamento de Morfologia e Fisiologia Animal da FCAVJ-UNESP para preparo histopatológico de rotina, com inclusão em parafina e coloração com Hematoxilina e Eosina (HE) e Tricrômico de Masson (TM), segundo técnicas descritas por TOLOSA et al. (2003), além de inclusão em historesina, com coloração em Hematoxilina e Eosina (HE) e Azul de Toluidina (AT).

\section{RESULTADOS E DISCUSSÃO}

Durante a avaliação clínica diária, observou-se, nos quatro primeiros dias, que a região adjacente à ferida cirúrgica apresentava rubor e sensibilidade dolorosa ao toque, entretanto, não foram constatadas alterações dignas de nota no estado geral dos animais, tampouco no aspecto da urina e das fezes. Estas constatações assemelham-se, em parte, aos relatos de KROPP (1998), ao implantar membrana composta por submucosa intestinal suína (SIS), na bexiga de ratos e de cães, e às descrições de GRECA et al. (2004) ao utilizarem a SIS na reparação de defeito vesical, em cães.

No presente estudo, em decorrência do emprego do peritônio bovino, assim como na utilização da membrana SIS na bexiga de cães (GRECA et al., 2004), não ocorreu nenhum caso de óbito. Isso foi verificado em sete dos 40 ratos que receberam implante vesical de membrana composta por matriz de tecido acelular derivada da parede gástrica e vesical (SUTHERLAND et al., 1996) e em um dos 18 coelhos, após cistoplastia com matriz extracelular derivada de 
tecido vesical homólogo (YANG et al., 2005). Segundo SUTHERLAND et al. (1996), este evento ocorreu na fase “piloto” de seu experimento. Já YANG et al. (2005), referem como causa do óbito uma reação imunogênica ao material implantado, embora estes autores não citassem qual foi o procedimento empregado no processamento da membrana, nem realizaram a análise histopatológica para a confirmação deste fato.

Em todos os coelhos, a temperatura retal manteve-se no padrão fisiológico para a espécie, ou seja, entre $38,6^{\circ} \mathrm{C} \mathrm{e} 40^{\circ} \mathrm{C}$ (REECE, 1999).

Não foi obsevada, em nenhum dos coelhos deste estudo, a ocorrência de deiscências de sutura, conforme foi constatado em dois dos 13 cães, nos quais DALECK et al. (1992) utilizaram membrana peritoneal bovina para reparo de hérnia perineal e em $42,86 \%$ dos gatos, que receberam implante vesical de membrana de pericárdio caprino (GURGEL \& CORTEZ FILHO, 2001).

Nesta oportunidade, não foram observados, em nenhum dos animais, sinais macroscópicos de rejeição ou falha no implante tal qual relataram DALECK et al. (1992). Além disso, não foram verificadas, nas bexigas ora analisadas, presença de muco e sinais de necrose ou de fístula, eventos que se caracterizam por complicações, as quais, geralmente, são encontradas após a utilização de implantes vesicais como registraram ELBAHNASY et al. (1998), KROPP (1998), YOO et al. (1998), YAMATAKA et al. (2003) e NUININGA et al. (2004).

Em todos os períodos de observação, havia aderências da região do implante com o peritônio parietal da parede ventral do abdômen. Aos sete e aos 14 dias de pós-operatório, os testículos estavam aderidos ao local da cistoplastia e aos 60 dias notou-se aderência de ceco e de segmento de jejuno (Figura 1B) ao sítio do implante. Estes achados corroboram aos de DALECK et al. (1989), ao verificarem aderências do intestino delgado, reto e epiplon, após cistoplastia dorsal, em cães, com membrana peritoneal bovina, e aos de SUTHERLAND et al. (1996), que encontraram aderências da uretra, ovário, tuba uterina e omento à região de reparo vesical, em ratos, com membrana composta por matriz de tecido acelular derivada da parede gástrica e vesical, oriundas desta mesma espécie. Além disso, no emprego de retalho de peritônio bovino, tanto em substituição a segmento diafragmático (DALECK et al., 1988), quanto na tenoplastia do tendão calcanear (COSTA NETO et al., 1999), ambos na espécie canina, foi observada a ocorrência de aderências entre algumas das estruturas adjacentes.

As aderências pós-cirúrgicas que ocorrem na cavidade peritonial são decorrentes de baixa atividade fibrinolítica no local da lesão cirúrgica, favorecendo o acúmulo de matriz de fibrina e, conseqüentemente, uma fibroproliferação, que se caracteriza por adesão (LIAKAKOS et al., 2001).

Verificou-se, nesta oportunidade, que os implantes propiciaram a formação de cálculos (PENTERMANN et al., 1985; SUTHERLAND et al.,1996; ELBAHNASY et al., 1998; KROPP, 1998; YOO et al., 1998; YAMATAKA et al., 2003; NUININGA et al., 2004), constituídos por carbonato de cálcio, e não por estruvita, oxalato de cálcio e fosfato de cálcio, conforme constataram SUTHERLAND et al., (1996) e NUININGA et al., (2004). Contudo, YANG et al. (2005) não observaram a presença de cálculos, depois do implante de membrana derivada de tecido vesical homólogo, na bexiga de coelhos.

A urina, em todas as amostras coletadas, apresentou aspecto turvo, densidade média de 1,030, pH 8 a 9, cristalúria composta por carbonato de cálcio e traços de proteína. Nenhum autor fez referência à urinálise, exceto NUININGA et al. (2004), ao citarem que a urina dos coelhos que receberam o implante de SIS apresentou pH de 7,5 a 8,5, com altos níveis de urato.

Provavelmente as alterações urinárias constatadas neste estudo devem-se tanto ao emprego de implante, quanto ao do fio de sutura, materiais estranhos ao tecido vesical, que, além de ocasionarem alterações na parede da bexiga, serviram de base para a agregação e formação de cálculos (MORRIS et al., 1986). Outro possível fator para essa ocorrência relaciona-se ao tipo de dieta oferecida aos animais, pois as rações comerciais para coelhos são alcalinas, elevando o pH urinário e favorecendo a cristalúria (KIWULL-SCHÖNE et al., 2005).

Na análise histopatológica da interface do implante com o tecido nativo dos coelhos submetidos à eutanásia aos sete dias de pós-operatório, como observado na esofagoplastia cervical de cães (DALECK et al., 1987), as fibras musculares e a lâmina própria estavam ausentes e havia descontinuidade do epitélio. Estes achados diferem dos registros de SUTHERLAND et al. (1996) e de YANG et al. (2005), que constataram início de reepitelização e presença de células musculares no quarto dia e no sétimo dia de pós-operatório, respectivamente. Supõe-se nesses casos que a presença, tanto de tecido acelular derivado de parede vesical (SUTHERLAND et al., 1996), quanto de matriz extracelular derivada de bexiga homóloga (YANG et al., 2005), utilizados como implantes, tenham propiciado o aparecimento precoce de urotélio.

Ainda aos sete dias de pós-operatório, observou-se, na periferia do implante, a presença de intenso infiltrado inflamatório misto constituído por 
células polimorfonucleares (PMN) e mononucleares $(\mathrm{MN})$, proliferação de fibras colágenas e neovascularização (Figura 2A), conforme ocorrido mediante o emprego de fragmento de peritônio para reparação esofágica (DALECK et al., 1987) e a substituição de retalho diafragmático (DALECK et al., 1988) em cães. Estas observações sugerem a evolução do processo de reparação tecidual, caracterizado, neste período, pelas fases de inflamação e de fibroplasia (RINGLER, 2000).

Nas amostras referentes aos animais submetidos à eutanásia aos 14 dias de pós-operatório, observadas à microscopia de luz, a lâmina própria e o epitélio estavam ausentes, havia presença de intenso infiltrado inflamatório misto, além de acentuada neovascularização (Figura 2B), à semelhança de outros estudos (DALECK et al., 1987; DALECK et al., 1988; NUININGA et al., 2004). Entretanto, KROPP (1998) visibilizou, aos 15 dias de pós-operatório, urotelização completa no local de implante de SIS, o que, de acordo com o autor, pode estar relacionada a fatores intrínsecos deste biopolímero.

Observou-se ainda neste período a presença de fibras colágenas neoformadas, entremeadas às escassas fibras musculares, ambas distribuídas de maneira desorganizada (Figura 2B), situação esta também descrita por SUTHERLAND et al. (1996) e por KROPP (1998). Nesta etapa da reparação tecidual, ocorre a transição da fase fibroblástica para o início da fase de maturação e remodelação, que pode perdurar por meses e até mesmo por anos (RINGLER, 2000).

Nas amostras pertencentes aos coelhos submetidos à eutanásia aos 30 dias de pós-operatório, verificou-se, durante avaliação histopatológica, que a membrana implantada ainda se encontrava presente

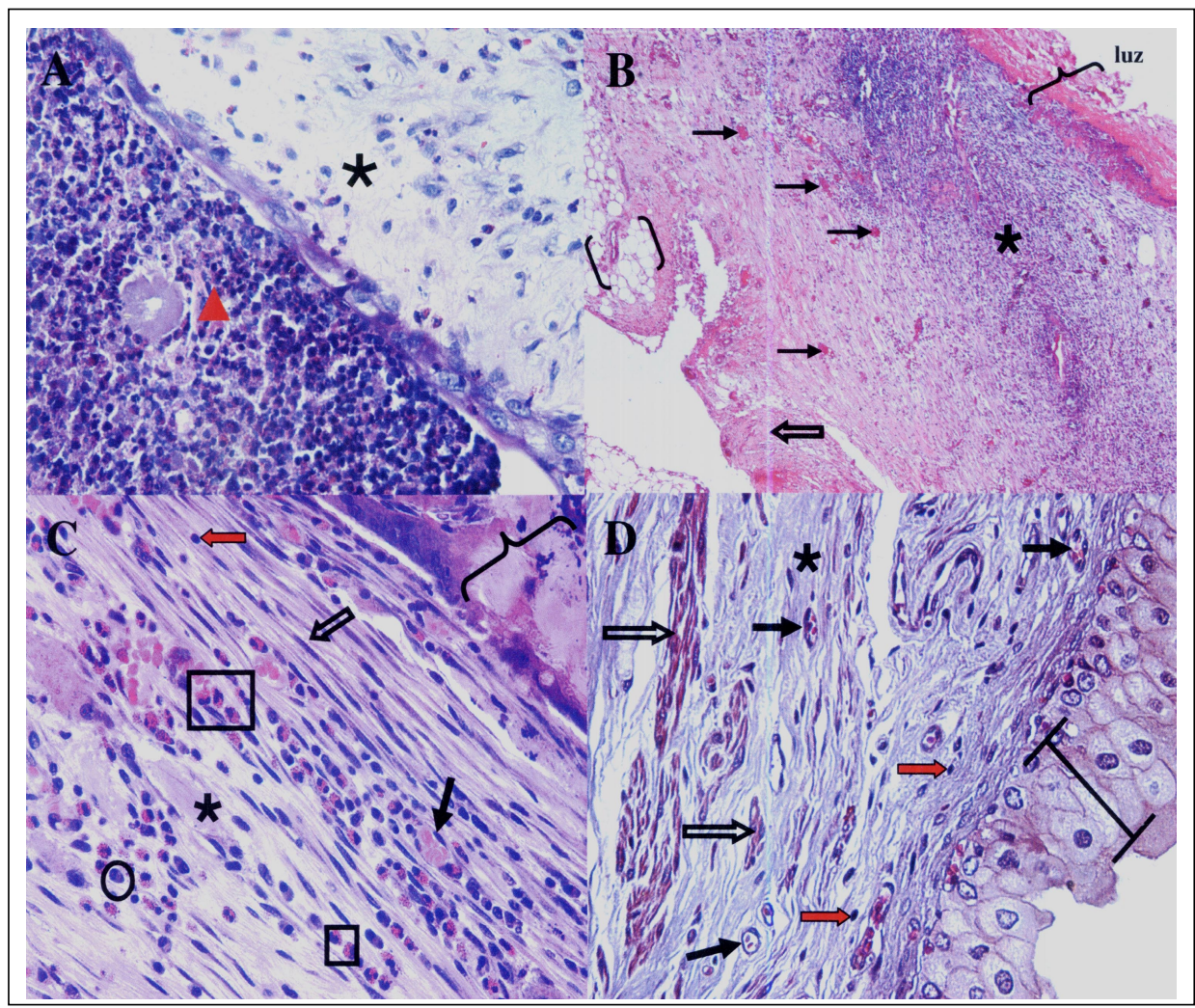

Figura 2 - Fotomicrografia da região do implate de biomembrana na bexiga de colelho, macho, adulto, da raça Nova Zelândia. Em A, aos sete dias de pós-operatório, foram observadas a área de transição do tecido nativo $\left({ }^{*}\right)$ e a região de implante, com infiltrado inflamatório misto ( $\left.\mathbf{\Delta}\right)$ (Paraplast, HE, 40X). Em B, aos 14 dias de pós-operatório, foram constatados o pertiônio bovino ( $\{$ ) voltado para a luz do órgão, as fibras musculares $(\Rightarrow)$, as fibras colágenas com células inflamatórias $(*)$, os neovasos $(\rightarrow)$ e tecido adiposo na região da serosa ([]) (Paraplast, HE, 5X). Em C, aos 30 dias de pós-operatório, verificam-se a membrana perotôneal bovina $(\{)$, os pseudo-eosinófilos $(€)$, os linfócitos $(\Rightarrow)$, os macrófagos $(\mathbf{0})$, os neovasos $(\rightarrow)$, as fibras musculares $(\Rightarrow)$ e as fibras colágenas $(*)$ (Historesina, HE, 40X). Em D, aos 60 dias de pósoperatório, nota-se a presença de epitélio $(\mapsto)$, vasos sangüíneos $(\rightarrow)$, fibras musculares $(\Rightarrow)$, as fibras colágenas $(*)$ e linfócitos $(\rightarrow)$ (Paraplast, TM, 40X).

Ciência Rural, v.38, n.8, nov, 2008. 
(Figura 2C). Este fato também ocorreu após a substituição de retalho diafragmático de cães, por segmento de peritônio bovino (DALECK et al., 1988), e posteriormente à utilização desta mesma membrana biológica na tenoplastia do tendão calcâneo comum, em cães (COSTA NETO et al., 1999). Todavia, neste mesmo tempo de avaliação, DALECK et al. (1987) não observaram a permanência do implante de peritônio autólogo ou homólogo na região da esofagoplastia cervical canina por eles realizada.

Ainda aos 30 dias de pós-operatório, havia presença de intenso infiltrado inflamatório misto, fibras colágenas mais organizadas, neovascularização e escassos feixes musculares (Figura 2C), porém, no local do implante, não havia lâmina própria e nem epitélio, diferindo, neste aspecto, das observações referentes aos animais que receberam implante de peritônio autólogo ou homólogo em defeito esofágico (DALECK et al., 1987) e daqueles em que a membrana SIS foi implantada como retalho vesical (KROPP, 1998; GRECA et al., 2004).

Aos 60 dias de pós-operatório, observouse, sob microscopia de luz, que a parede vesical apresentava-se totalmente reconstituída. Foi possível verificar completa reepitelização, presença de lâmina própria, fibras colágenas organizadas, algumas fibras musculares e escassas células inflamatórias mononucleares (Figura 2D), corroborando as descrições de DALECK et al. (1987), DALECK et al. (1988) e de COSTA NETO et al. (1999).

Em todas as amostras avaliadas aos 60 dias, notou-se a ausência da membrana peritônio bovino, bem como ocorreu após reparo esofágico canino com retalho peritonial autólogo ou homólogo (DALECK et al., 1987). No entanto, em um mesmo período de observação, DALECK et al. (1988), no local de reparação diafragmática, e COSTA NETO et al. (1999), na tenoplastia de cães, relataram que o implante ainda se encontrava presente. Para serem obtidos dados mais conclusivos sobre este evento, pesquisas comparativas voltadas ao processo de reparação e morfofuncionalidade dos órgãos receptores devem ser conduzidas.

Em nenhum dos tempos avaliados havia a presença de mineralização e metaplasia óssea no local do implante, como constatado por DALECK et al. (1989) após reparação vesical de cães com peritônio bovino, embora estes autores não tenham feito referência sobre o tempo de observação em que verificaram esta ocorrência. Talvez a mineralização e a metaplasia óssea sejam características intrínsecas da espécie canina frente ao implante deste biomaterial, haja vista que nos coelhos deste estudo isso não ocorreu. Mesmo assim, há necessidade da realização de pesquisas que possam auxiliar no esclarecimento deste fato.

\section{CONCLUSÃO}

Com base nos resultados histológicos obtidos, pôde-se concluir que o peritônio bovino conservado em glicerol a $98 \%$ fornece arcabouço para orientação e desenvolvimento dos tecidos vesicais, mediante processos de reparação, restabelecendo, aos 60 dias de pós-operatório, os tecidos que compõem o órgão. Além disso, vale ressaltar que o implante é biocompatível, uma vez que não provoca reação do tipo corpo estranho.

\section{AGRADECIMENTOS}

Os autores agradecem ao Prof. Dr. Joaquim Coutinho Netto, do Depto. de Bioquímica e Imunologia da Faculdade de Medicina de Ribeirão Preto, Universidade de São Paulo (USP), pela colaboração no desenvolvimento deste estudo e à Fundação de Amparo à Pesquisa do Estado de São Paulo (FAPESP), pelas bolsas de mestrado (processo FAPESP no 05/ 52927-4) e de iniciação científica (processo FAPESP no 02/ 11864) e pelo auxílio concedido (processo FAPESP no 06/ 51057-9) concedidos.

\section{COMITÊ DE ÉTICA}

A pesquisa desenvolvida foi previamente aprovada pela Comissão de Ética e Bem-Estar Animal (CEBEA) da FCAVJUNESP, sob protocolo no 023232-05, de acordo com os Princípios Éticos na Experimentação Animal, adotado pelo Colégio Brasileiro de Experimentação Animal (COBEA).

\section{REFERÊNCIAS}

ALVARENGA, J. Possibilidades e limitações da utilização de membranas biológicas preservadas em cirurgia. In: DALECK, C.R. et al. Tópicos em cirurgia de cães e gatos. Jaboticabal: FUNEP-UNESP, 1992. p.33-42.

COSTA NETO, J.M. et al. Tenoplastia experimental do calcâneo em cães com peritônio bovino conservado em glicerina. Ciência Rural, Santa Maria, v.29, n.4, p.697-703, 1999.

DALECK, C.R. et al. Esofagoplastia cervical no cão com peritônio autólogo ou homólogo conservado em glicerina “estudo experimental”. Ars Veterinária, Jaboticabal, v.3, n.2, p.195-202, 1987

DALECK, C.R. et al. Substituição de um retalho diafragmático de cão por peritônio de bovino conservado em glicerina: estudo experimental. Ars Veterinária, Jaboticabal, v.4, n.1, p.5361, 1988.

DALECK, C.L.M. et al. Cistoplastia com peritônio autólogo em cães. Semina, Londrina, v.10, n.1, p.22-26, 1989.

DALECK, C.R. et al. Reparação de hérnia perineal em cães com peritônio de bovino conservado em glicerina. Ciência Rural, Santa Maria, v.22, n.2, p.179-183, 1992. 
ELBAHNASY, A.M. et al. Bladder wall substitution with synthetic and non-intestinal organic materials. Journal of Urology, Baltimore, v.159, p.628-637, 1998.

FOSSUM, T.W. Cirurgia da bexiga e da uretra. In: Cirurgia de pequenos animais. São Paulo: Roca, 2002. Cap.22, p.533-570.

GRECA, F.H. et al. Utilização da submucosa de intestino delgado porcino como retalho para aumento da capacidade vesical em cães. Acta Cirúrgica Brasileira, São Paulo, v.19, n.6, 2004.

GURGEL, S.; CORTEZ FILHO, J.J. Uso do pericárdio caprino conservado em glicerina no reparo de bexiga de Felis catus. In: CONGRESSO BRASILEIRO DE CLÍNICOS VETERINÁRIOS DE PEQUENOS ANIMAIS, 22., 2001, Fortaleza. Anais... Fortaleza: Faculdade de Veterinária - Universidade Estadual do Ceará, 2001. p.169.

KIWULL-SCHÖNE, H. et al. Food mineral composition and acid-base balance in rabbits. European Journal of Nutrition, Steinkopff, v.44, n.8, p.499-508, 2005.

KROPP, B.P. Small-intestinal submucosa for bladder augmentation: a review of preclinical studies. World Journal of Urology, Baltimore, v.16, p.262-267, 1998.

LIAKAKOS, T. et al. Peritoneal adhesions: etiology, pathophysiology, and clinical significance. Recent advances in prevention and management. Digestive Surgery, Basel, v.18, p.260-273, 2001.

MORRIS, M.C. et al. Urolithiasis on absorbable and nonabsorbable suture materials in the rabbit bladder. Journal of Urology, Baltimore, v.135, p.602-603, 1986.

NUININGA, J.E. et al. A rabbit model to tissue engineer the bladder. Biomaterials, Guildford, v.25, p.1657-1661, 2004.

PENTERMANN, E.J. et al. Prerequisites for urinary bladder design. Transaction American Society for Artificial Internal Organs, Hagerstown, v.31, p.308-312, 1985.
PIGOSSI, N. et al. Estudo experimental e clínico sobre o emprego, como implante, da dura-máter homógena conservada em glicerina à temperatura ambiente. Revista da Associação Médica Brasileira, São Paulo, v.17, n.08, p.263-278, 1967.

REECE, W.O. Regulação da temperatura e fisiologia ambiental. In: SWENSON, M.J.; REECE, W.O. Fisiologia dos animais domésticos. 11.ed. Rio de Janeiro: Guanabara Koogan, 1999. Cap.47, p.805-813.

RINGLER, D.J. Inflamação e reparo. In: JONES, T.C. et al. Patologia veterinária. São Paulo: Manole, 2000. Cap.5, p.119-165.

STONE, E.A. Bexiga. In: BOJRAB, M.J. Técnicas atuais em cirurgia de pequenos animais. 3.ed. São Paulo: Roca, 1996. Cap.26, p.355-356.

SUTHERLAND, R.S. et al. Regeneration of bladder urothelium, smooth muscle, blood vessels and nerves into an acellular tissue matrix. Journal of Urology, Baltimore, v.156, p.571-577, 1996.

TOLOSA, E.M.C. et al. Manual de técnicas para histologia normal e patológica. 2.ed. São Paulo: Manole, 2003. p.37.

YAMATAKA. A. et al. Living-related partial bladder transplantation for bladder augmentation in rats: an experimental study. Journal of Pediatric Surgery, Philadelphia, v.38, n.6, p.913-915, 2003.

YANG, S. et al. Experimental bladder defect in rabbit repaired with homologous bladder extracellular matrix graft. Chinese Medical Journal, Beijing, v.118, n.11, p.957-960, 2005.

YOO, J.J. et al. Bladder augmentation using allogenic bladder submucosa seeded with cells. Urology, Secaucus, v.51, n.2, p.221-225, 1998. 